machines, efficient transportation of dust-forming substances and by application of wet methods of boring, crushing, grinding, and polishing. Regulations control the maximum permissible concentration of toxic substances in the air of factories.

\section{Supply of Vitamin C}

Where large numbers of workers were moved to new localities there was often great difficulty in providing adequate amounts of fresh vegetables. Deficiency of vitamin $\mathrm{C}$ was made up by giving extracts of Ural pine or fir needles, or infusions of Siberian pine or larch, containing often as much as 200-300 mg. of ascorbic acid per $100 \mathrm{gm}$. of pine needles.

\section{Health of Women Workers}

There has been a great increase in the number of women factory workers. They showed, generally speaking, a lower incidence of accidents and of skin infections-probably owing to their greater attention to safety regulations and better personal hygiene than men. Excluding absence for pregnancy, or to attend to sick children, they showed also a lower sickness rate than men. On the other hand, they were slightly more susceptible to industrial poisoning, especially by T.N.T. Special medical services for women have been set up in many factories, including gynaecological and antenatal clinics, day nurseries and 'Feminine hygiene rooms' in some of the larger plants.

Under the stress of war the aim of Soviet industrial hygiene has been to reduce occupational risks and prevent sickness among factory workers, and to conduct experimental and theoretical research on various problems of industrial hygiene and toxicology, and thus to contribute to the advance of science as a whole and to the effort of the Soviet people to defend their country and expel the Hitlerite invaders.

\title{
HEATING AND VENTILATION : REQUIREMENTS AND METHODS
}

\author{
Addendum to Paper by T. BEDFORD. (This Journal, Vol. I, No. 1, p. 31)
}

On p. 35 reference was made to the scale of equivalent warmth, derived by Bedford (1936), by which the combined effects of the four factors which make up the thermal environment can be expressed in a single figure. The equivalent warmth was defined as the temperature of a uniform enclosure, with air and surroundings at the same temperature, and with the air still and saturated with water vapour, which would produce a sensation of warmth equal to that evoked by the combination of radiation and air temperature, velocity and humidity in question.

Through an oversight no mention was made of two other developments concerning the concept of equivalent warmth. Dufton (1936) proposed that the scale should be referred to semi-saturated and not saturated air, mainly on the ground that under extreme humidity conditions there is a difference between sensations of warmth and of comfort.
This view was taken later by the Joint Committee (of the Medical Research Council and the Department of Scientific and Industrial Research) on Research in Heating and Ventilation, which provisionally defined the equivalent warmth of an environment as 'that temperature of a uniform enclosure in which, in semi-saturated air, equal warmth would be experienced' (Douglas, 1938).

In his 1936 paper, Dufton gave a chart which, in the absence of appreciable radiation, enables equivalent warmth to be determined for various temperatures, humidities and degrees of air movement.

\section{REFERENCES}

Bedford, T. (1936). Indust. Hlth. Res. Bd. Rept. No. 76.

Douglas, C. G. (1938). App. I to Rept. of the Building Research Board for the year 1937.

Dufton, A. F. (1936). J. Instn. Heat. \& Vent. Engrs., 4, 181 . 